\title{
Exploring the associations between sleep problems and chronic musculoskeletal pain in adolescents: A prospective cohort study
}

\author{
Lee Harrison $\mathrm{MSc}^{1}$, Sue Wilson $\mathrm{PhD}^{2}$, Marcus R Munafò PhD ${ }^{3,4}$
}

\begin{abstract}
L Harrison, S Wilson, MR Munafò. Exploring the associations between sleep problems and chronic musculoskeletal pain in adolescents: A prospective cohort study. Pain Res Manag 2014;19(5):e139-e145.
\end{abstract}

BACKGROUND: The prevalence of musculoskeletal chronic pain in adolescents is estimated to be approximately $4 \%$ to $40 \%$. The development of musculoskeletal pain during teenage years could have a marked impact on physical, psychological and social well-being.

OBJECTIVE: To examine whether sleep problems during adolescence are associated with musculoskeletal pain, particularly chronic regional pain and chronic widespread pain.

METHODS: Using data from the Avon Longitudinal Study of Children, the relationship between sleep problems at 15 years of age and the presence of chronic regional and widespread pain at 17 years of age was explored. Pain data were not available at 15 years of age. A total of 2493 participants with complete data were identified. Relationships among sleep problems and musculoskeletal pain were examined using logistic regression. ORs were calculated after adjusting for sex, ethnicity, socioeconomic position and depression ( 15 years of age).

RESULTS: Sleep disturbance (usually wakes up more than two or three times), difficulties with hypersomnolence and poor subjective sleep perception were associated with the presence of both musculoskeletal regional and widespread pain. Finally, using ordered logistic regression, poor subjective sleep perception was also found to be associated with greater pain severity in participants with chronic musculoskeletal regional and widespread pain.

DISCUSSION: The results of the present study suggest an association between sleep problems during adolescence and the presence of musculoskeletal pain at a later stage. These findings are consistent with adult literature suggesting a link between sleep problems and musculoskeletal pain. Given these associations, sleep problems in adolescence may be an important risk factor for musculoskeletal pain.

Key Words: Adolescence; ALSPAC; Chronic pain; Sleep

\author{
Explorer les associations entre les troubles du \\ sommeil et les douleurs musculosquelettiques \\ chroniques chez les adolescents : une étude de \\ cohorte prospective
}

HISTORIQUE : On estime que la prévalence de douleur musculosquelet-
tique chronique se situe entre $4 \%$ et $40 \%$ chez les adolescents. L'apparition
de douleurs musculosquelettiques à l'adolescence peut avoir des répercus-
sions marquées sur le bien-être physique, psychologique et social.
OBJECTIF : Examiner si les troubles du sommeil pendant l'adolescence
s'associent aux douleurs musculosquelettiques, notamment les douleurs
régionales chroniques et les douleurs généralisées chroniques.
MÉTHODOLOGIE : À l'aide de données tirée de l'étude longitudinale
Avon auprès des enfants, les chercheurs ont exploré le lien entre les trou-
bles du sommeil à 15 ans et les douleurs régionales et généralisées chro-
niques à 17 ans. Il n'y avait pas de données sur la douleur à 15 ans. Au total,
on possédait des données complètes sur 2493 participants. On a examiné
les liens entre les troubles du sommeil et les douleurs musculosquelettiques
à l'aide de la régression logistique. Ils ont calculé les rapports de cote après
rajustementen fonction du sexe, del'ethnie, de la situation socioéconomique
et de la dépression (15 ans). RÉSULTATS : Les troubles du sommeil (en général, plus de deux ou trois réveils), les problèmes d'hypersomnolence et la perception subjective de mauvaise qualité de sommeil s'associaient à la présence de douleurs musculosquelettiques régionales et généralisées. Enfin, au moyen de la régression logistique ordonnée, une perception subjective de sommeil de mauvaise qualité s'associait également à une douleur plus grave chez les participants souffrant de douleurs musculosquelettiques généralisées et chroniques.

EXPOSÉ : Les résultats de la présente étude sont indicateurs d'une association entre les troubles du sommeil à l'adolescence et la présence de douleurs musculosquelettiques plus tard. Ces observations sont conformes aux publications pour adultes, qui indiquent un lien entre les troubles du sommeil et les douleurs musculosquelettiques. Compte tenu de ces associations, les troubles du sommeil à l'adolescence peuvent constituer un important facteur de risque de douleurs musculosquelettiques.

recommended $9 \mathrm{~h}$ to $10 \mathrm{~h}$ per night, and instead exhibit a higher incidence of sleep supplementation (eg, daytime napping) (5). Other problems include a greater number of wakes per night, longer sleep onset latencies $(>30 \mathrm{~min}$ ) and dramatic shifts in sleep-wake schedules across the week $(6,7)$. Such disturbances significantly disrupt the homeostatic sleep-wake cycle, which causes excessive sleepiness and ultimately affects behavioural, cognitive and emotional functioning $(8,9)$.

Sleep and pain share a complex, reciprocal relationship: pain can disrupt sleep and, conversely, poor sleep can exacerbate pain intensity $(10,11)$. Sleep problems have long been linked to musculoskeletal pain (12) and, in particular, chronic widespread pain (CWP). Longitudinal studies in adult populations have found sleep problems to leep problems are becoming increasingly prevalent among adoles-
cents, rising from $31.2 \%$ in 2003 to $41.9 \%$ in 2012 (1). Such problems are characterized as poor sleep hygiene and, in particular, difficulties initiating or maintaining sleep. Negative perceptions of sleep, such as rumination over bad sleep quality, are also likely to arise that specifically musculoskeletal pain (2-4). The present study aimed to explore the association, if any, between sleep problems and the presence of musculoskeletal pain in a large adolescent cohort.

Both sleep quality and quantity undergo significant changes during adolescence due to the increased risk of sleep disturbance during this period. Specifically, adolescents rarely sleep for the
${ }^{1}$ School of Social and Community Medicine, University of Bristol, Bristol; ${ }^{2}$ Centre for Neuropsychopharmacology, Division of Brain Sciences, Imperial
College London, Burlington Danes Building, Hammersmith Hospital campus, London; ${ }^{3} \mathrm{MRC}$ Integrative Epidemiology Unit; ${ }^{4}$ UK Centre for
Tobacco and Alcohol Studies, School of Experimental Psychology, University of Bristol, Bristol, United Kingdom
Correspondence: Ms Lee Harrison, School of Social and Community Medicine, University of Bristol, Oakfield House, Oakfield Grove,
Bristol BS8 2BN, United Kingdom. Telephone 0117-331-0143, e-mail lee.harrison@bristol.ac.uk This open-access article is distributed under the terms of the Creative Commons Attribution Non-Commercial License (CC BY-NC) (http:// OPEN ACCESS creativecommons.org/licenses/by-nc/4.0/), which permits reuse, distribution and reproduction of the article, provided that the original work is properly cited and the reuse is restricted to noncommercial purposes. For commercial reuse, contact support@pulsus.com 


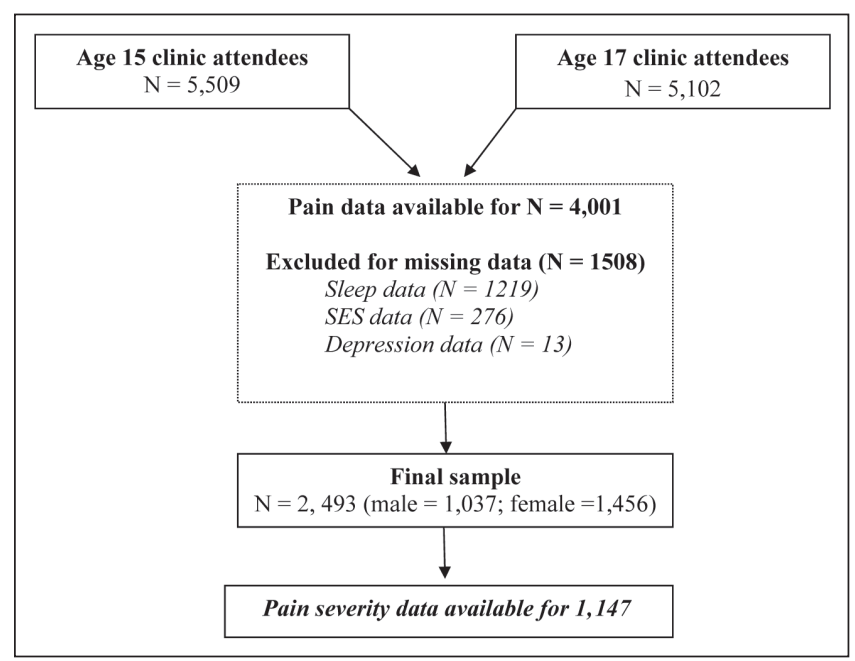

Figure 1) Flow chart of participants included in final and subgroup analyses; SES Socioeconomic status

be predictive of CWP and disorders such as fibromyalgia $(13,14)$. Similar studies also found that good-quality restorative sleep was more likely to predict the resolution of pain symptoms and the subsequent return to musculoskeletal health in patients with CWP (15). Currently, little is known about the role of sleep in adolescent pain populations such as those with juvenile fibromyalgia.

The prevalence of musculoskeletal pain in adolescence is estimated to be approximately $4 \%$ to $40 \%$ (16). The development of musculoskeletal pain during this time could have significant ramifications for an adolescent's developmental trajectory, impacting an adolescent's physical, emotional and social well-being. Adolescents may miss school and have reduced engagement with social and recreational activities. Chronic musculoskeletal pain also poses a significant developmental health concern in terms of a child's mental health, impacting negatively on mood, somatic internalization and attentional factors (17). It is, therefore, critical that any potential risk factors are identified in early childhood.

Problematic sleep has been found to increase pain sensitivity and facilitate pain episodes in both animal and adult populations $(11,18,19)$. A growing body of evidence suggests that sleep problems pose an important risk for the development of musculoskeletal pain in adolescents. A large cross-sectional study involving 6986 adolescents found short sleep time to be a risk factor associated with regional musculoskeletal pain (20). A prospective four-year study followed children with musculoskeletal pain from 10 to 14 years of age and found tiredness and difficulty falling asleep to be predictive factors of recurrent pain (2). Similarly, another longitudinal study involving 1773 adolescents identified insufficient sleep at 16 years of age as a risk factor for the development of neck and lower back pain in girls at 18 years of age (21). Finally, factors such as daytime hypersomnolence and sleep disturbance are also associated with an increased likelihood of developing chronic musculoskeletal pain (4). Such studies complement longitudinal studies from adult cohorts suggesting that late-onset insomnia can predict both the development of a pain condition and pain severity $(22,23)$.

Previous studies have focused mainly on localized or regional pain; therefore, the determinants of widespread musculoskeletal pain are not well known. Importantly, we need to better understand the role of sleep in widespread pain conditions such as juvenile fibromyalgia. The present study had two aims. First, we sought to explore the prevalence of chronic regional pain (CRP) and CWP in a large birth cohort. Second, by using fibromyalgia definitions to identify those with CWP, we sought to explore which characteristics of sleep were associated with such pain outcomes. Specifically, we explored the association between a variety of sleep problems at 15 years of age (eg, disturbance, hypersomnolence) and both CRP and CWP at 17 years of age. We hypothesised that subjective sleep problems at 15 years of age would be associated with musculoskeletal pain and increased pain severity at 17 years of age.

\section{METHODS}

\section{Participants}

The Avon Longitudinal Study of Parents and Children (ALSPAC) (24) is a prospective population-based study investigating a wide range of genetic and environmental influences on the health and development of children. Between April 1, 1991 to December 31, 1992, 14,541 pregnant women were initially enrolled from the district formerly known as Avon (United Kingdom). A total of 14,062 children were born and 13,988 were alive at 12 months of age. The main focus of the present study was the results obtained from research clinics held at 15 and 17 years of age. A total of 5509 children attended the research clinic at 15 years of age and 5102 attended at 17 years of age. For the variables of interest, a complete data set was available for 2493 participants. Given that data were only available for $45 \%$ of individuals who attended the clinic at 15 years of age, $\chi^{2}$ tests were used to establish whether there were any differences in the variables of interest between those with and without data. Analyses showed that the groups differed according to sex $\left(\chi^{2}[1]=57.53 ; \mathrm{P}<0.001\right)$ and socioeconomic status $\left(\chi^{2}[6]=41.15, \mathrm{P}<0.001\right)$. The flow chart (Figure 1) shows the selection of adolescents who comprised the final sample for analysis. Ethics approval for the study was obtained from the ALSPAC Ethics and Law Committee and the local Research Ethics Committees.

\section{Pain questionnaire}

The pain questionnaire was administered to all participants attending a research clinic at 17 years of age. Based on combinations of pain previously reported in the literature, the questionnaire was assembled from domains and scales taken from previously validated questionnaires (25-27). The questionnaire covered three aspects of pain: the experience of localized pain, the overall experience of pain and the impact of pain on aspects of life.

Initially, participants indicated whether they had experienced any aches or pains that had lasted for longer than one day in the past month and, if so, whether this had started in the past three months, or before. Using a mannequin, they were asked to indicate the site of the pain. Participants were then provided with a list of regions (eg, shoulder, knee) and asked to indicate whether they had experienced no pain or pain ranging from not at all to slightly, moderately, very or extremely troubling. Choosing their most troublesome pain, they were asked to indicate whether, over the past three to six months, their pain had lasted for $<7$ days, one to four weeks, one to three months or $\geq 3$ months. Finally, as part of the Chronic Pain Grade Questionnaire (27) participants were asked to rate their average pain severity over the past six months on a scale of 1 (no pain at all) to 10 (worst pain imaginable). Only 1147 (46.0\%) of the adolescents completed this final measure.

Based on the participants' experience of chronic pain (pain lasting $\geq 3$ months) variables were derived from pain patterns consistent with clinical phenotypes and, in particular, musculoskeletal pain (28). Two forms of musculoskeletal pain were identified: CRP and CWP. CRP comprised of moderately, very or extremely troublesome pain lasting $>3$ months affecting the knee, hip, shoulder, lower back or a combination of these sites, as indicated by completion of the troublesome pain domain. CWP was based on diagnostic criteria for fibromyalgia (ie, pain on both sides of the body, above and below the waist and in the axial skeleton that has been present for $\geq 3$ months), based on completion of the pain mannequin (29). Specifically, CWP comprised of pain lasting $>3$ months, axial pain and upper left quadrant pain plus lower right quadrant pain (or vice versa), as assessed by completion of the pain mannequin. These definitions for both the CRP and CWP phenotypes were consistent with guidelines outlined by the American College of Rheumatology and have previously been used to assess musculoskeletal pain in a large population study (28). Unfortunately, no pain measures were administered before the 17 years of age clinic. 


\section{Sleep problems}

The participants had previously attended a research clinic at 15 years of age, at which they completed a sleep questionnaire that assessed aspects of their sleep pattern. Initially, participants were asked to rate whether they considered themselves to be a 'good' or a 'poor' sleeper. Sleep disturbance was assessed by asking participants how many times a night they usually woke up, to which they could answer: never, once, two or three times or $>3$ times. Hypersomnolence was also assessed by asking the children how much of a problem they had with sleepiness during daytime activities (eg, feeling sleepy, struggling to stay awake): no problem, a little problem, more than a little problem, a big problem and a very big problem. Finally, participants were asked to rate the perceived quantity of their sleep by rating how often they believed they got enough sleep: always, usually, sometimes, rarely, never. Due to the low number of observations within some response categories, certain questionnaire items were collapsed before analysis. For example, the responses 'rarely' and 'never' were combined into one category for the quantity question. These ordered response categories were collapsed so that a sufficient number of observations were included in each level of the logistic regression model. Levels were only collapsed if it was theoretically viable to do so, and subsequent analyses were examined to ensure that the models did not differ drastically. This was also performed for both the disturbance (two or three times/ $>3$ times) and hypersomnolence (big problem/very big problem) questions. Overall, reliability of the sleep questionnaire found to be acceptable (Cronbach's $\alpha=0.67$ ). To assess which characteristics of sleep were associated with musculoskeletal pain, each item was examined independently.

Sleep data was also collected at the 17 years of age clinic using a computerized version of the Clinical Interview Schedules - Revised (CIS-R). The interview is fully standardized and equally reliable whether conducted by a clinically trained interviewer or self-administered via a computer (30-32). The CIS-R is designed for and has been widely used within adolescent birth cohorts including National Surveys of Psychiatric Morbidity and the 1958 birth cohort (32-34). The CIS-R has 14 subsections, including an assessment of sleep problems. Specifically, the interview examines changes in sleep patterns, causes of sleep disturbance and duration of sleep to assess the severity of the sleep problem. Each subsection has a score of between zero and four, and a symptom with a score of $\geq 2$ should be considered a significant sleep problem. This criterion was used to identify adolescents with an identifiable sleep problem.

\section{Other measures}

Previous studies have found that both background factors (ethnicity, sex, socioeconomic status) and emotional factors are associated with recurrent pain across adolescence (35-37). To control for the potential influence from these factors, they were entered as covariates into the regression models. Specifically, depression was assessed using the Development and Well-Being Assessment when children were 15 years of age. This assessment is a self-report measure that inquires about psychiatric symptoms to generate International Classification of Diseases - 10th Revision diagnoses (38). The semistructured interview includes both open and closed questions about a range of symptoms related to childhood depression. The responses provide a likely diagnosis of depression where appropriate. Socioeconomic position indicators were obtained from self-administered questionnaires to the mothers. Social class was defined using the UK Registrar General's occupational coding (SOC 90) and grouped into six categories : I, professional; II, managerial and technical; III, skilled manual or nonmanual; IV, semiskilled manual; V, unskilled; VI, armed forces. The highest social class of either expectant parent was used to define parental social class. Sex and ethnicity were also recorded.

\section{Data analysis}

The relationship between sleep problems (15 years of age) and the presence of musculoskeletal pain (17 years of age) was examined using logistic regression. ORs were calculated for an unadjusted
TABLE 1

Demographic data for participants with and without musculoskeletal pain

\begin{tabular}{|c|c|c|c|c|}
\hline & \multicolumn{2}{|c|}{ Chronic regional pain } & \multicolumn{2}{|c|}{ Chronic widespread pain } \\
\hline & No & Yes & No & Yes \\
\hline Female & $1371(55.0)$ & $85(3.4)$ & $1380(55.4)$ & $76(3.1)$ \\
\hline Male & $1006(40.4)$ & $31(1.2)$ & $1012(40.6)$ & $25(1.0)$ \\
\hline \multicolumn{5}{|l|}{ Ethnicity } \\
\hline White & $2334(93.6)$ & $114(4.6)$ & $2329(93.4)$ & $99(4.0)$ \\
\hline Black African & $6(0.2)$ & $2(0.1)$ & $8(0.3)$ & $0(0.0)$ \\
\hline $\begin{array}{l}\text { Black } \\
\text { Caribbean }\end{array}$ & $1(0.0)$ & $0(0.0)$ & $1(0.0)$ & $0(0.0)$ \\
\hline Other Black & $2(0.1)$ & $0(0.0)$ & $2(0.1)$ & $0(0.0)$ \\
\hline Indian & $9(0.4)$ & $0(0.0)$ & $8(0.3)$ & $1(0.0)$ \\
\hline Pakistani & $1(0.0)$ & $0(0.0)$ & $1(0.0)$ & $0(0.0)$ \\
\hline Chinese & $9(0.4)$ & $0(0.0)$ & $9(0.4)$ & $0(0.0)$ \\
\hline Other & $15(0.6)$ & $0(0.0)$ & $14(0.6)$ & $1(0.0)$ \\
\hline \multicolumn{5}{|c|}{ Socioeconomic position } \\
\hline Class I & $125(5.1)$ & $5(0.2)$ & $126(5.1)$ & $4(0.2)$ \\
\hline Class II & $677(27.2)$ & $20(0.8)$ & $668(26.8)$ & $29(1.2)$ \\
\hline Class III & $689(27.6)$ & $43(1.7)$ & $710(28.5)$ & $22(0.9)$ \\
\hline Class IV & $553(22.2)$ & $31(1.2)$ & 557 (22.3) & $27(1.1)$ \\
\hline Class V & $275(11.0)$ & $14(0.6)$ & $272(10.9)$ & $17(0.7)$ \\
\hline Armed forces & $56(2.3)$ & $3(0.1)$ & $57(2.3)$ & $2(0.1)$ \\
\hline Don't know & $2(0.0)$ & $0(0.0)$ & $2(0.1)$ & $0(0.0)$ \\
\hline $\begin{array}{c}\text { Pain severity* } \\
\text { mean } \pm S D\end{array}$ & $4.16 \pm 2.07$ & $5.64 \pm 2.21$ & $4.21 \pm 2.08$ & $5.38 \pm 2.35$ \\
\hline
\end{tabular}

Data presented as $n$ (\%) unless otherwise indicated. *Out of 10

model, a model partially adjusted for sex, ethnicity and socioeconomic position and, finally, a fully adjusted model additionally controlling for depression at 15 years of age and current sleep problems (17 years of age). Specifically, associations between independent measures of sleep (subjective perception, hypersomnolence, disturbance and perceived quantity) at 15 years of age, and CWP and CRP at 17 years of age were analyzed. Ordered logistic regression was used to assess the influence of sleep problems on pain severity in those reporting CRP and CWP. Pain severity scores were initially scored on a 1 to 10 ordinal scale. Responses were categorized into three groups: no pain to mild pain $(1-4)$, moderate pain $(5-7)$ and severe pain (8-10). Specifically, pain severity was tested in individuals who considered themselves good and poor sleepers. All statistical analyses were conducted using Stata 12 . The study website contains details of all the data that are available through a fully searchable data dictionary $(38,39)$.

\section{RESULTS}

The sample was predominantly female $(n=1456$ [58.4\%]) and of European ancestry $(98.2 \%)$ For full demographic information, see Table 1. CRP was identified in $116(4.7 \%)$ of those sampled and 101 (4.1\%) were identified as having CWP. Both CRP and CWP were observed in 29 participants $(1.2 \%)$. Only 10.7\% ( $n=269)$ reported that they felt that they always had enough sleep. A total of $38.7 \%$ $(n=965)$ described not having any difficulties with hypersomnolence. More than one-half of the sample $(n=1408$ [56.5\%]) reported never having problems with waking up during the night. Finally, 15.2\% $(n=379)$ of the sample considered themselves to be poor sleepers. Full sleep characteristics of those with and without musculoskeletal pain are presented in Table 2.

Nearly one-half of the sample $(n=1138$ [45.6\%]) indicated 'yes' to having pain lasting for longer than one day in the past month. Eighteen of these however, failed to complete the pain mannequin. Of the remaining 1130 , nearly one-half $(n=481[42.5 \%])$ stated that the pain had been troublesome for less than seven days, while 293 (25.9\%) reported it had bothered them for between one and four weeks. Fewer 


\begin{tabular}{|c|c|c|c|c|}
\hline \multirow{2}{*}{$\begin{array}{l}\text { Types of sleep } \\
\text { disturbance }\end{array}$} & \multicolumn{2}{|c|}{ Chronic regional pain } & \multicolumn{2}{|c|}{ Chronic widespread pain } \\
\hline & No & Yes & No & Yes \\
\hline \multicolumn{5}{|c|}{ Do you consider yourself a: } \\
\hline Good sleeper & $2026(81.3)$ & $88(3.5)$ & $2038(81.7)$ & $76(3.0)$ \\
\hline Poor sleeper & $351(14.1)$ & $28(1.1)$ & $354(14.2)$ & $25(1.0)$ \\
\hline \multicolumn{5}{|l|}{ Usually wakes up: } \\
\hline Never & $1356(54.4)$ & $52(2.1)$ & $1367(54.8)$ & $41(1.6)$ \\
\hline Once & $719(28.8)$ & $40(1.6)$ & $722(29.0)$ & $37(1.5)$ \\
\hline $\begin{array}{r}2-3 \text { times/ } \\
>3 \text { times }\end{array}$ & $302(12.1)$ & $24(1.0)$ & $303(12.2)$ & $23(0.9)$ \\
\hline \multicolumn{5}{|c|}{ Problems with hypersomnolence: } \\
\hline Never & $916(36.7)$ & $49(2.0)$ & $934(37.5)$ & $31(1.2)$ \\
\hline A little & $1246(50.0)$ & $48(1.9)$ & $1245(49.9)$ & $49(2.0)$ \\
\hline More than a little & $166(6.7)$ & $8(0.3)$ & $159(6.4)$ & $15(0.6)$ \\
\hline Big/very big & $49(2.0)$ & $11(0.4)$ & $54(2.2)$ & $6(0.2)$ \\
\hline \multicolumn{5}{|l|}{ Enough sleep: } \\
\hline Always & $263(10.5)$ & $6(0.2)$ & $257(10.3)$ & $12(0.5)$ \\
\hline Usually & $1244(49.9)$ & $57(2.3)$ & $1258(50.5)$ & $43(1.7)$ \\
\hline Sometimes & $618(24.8)$ & $30(1.2)$ & $622(24.9)$ & $26(1.0)$ \\
\hline Rarely/never & $252(10.1)$ & $23(0.9)$ & $255(10.2)$ & $20(0.8)$ \\
\hline
\end{tabular}

Data presented as $n(\%)$

individuals reported having troublesome pain lasting between one and three months $(\mathrm{n}=185$ [16.4\%]) and $171(15.1 \%)$ had experienced troublesome pain for $>3$ months. The mean $( \pm \mathrm{SD}$ ) pain severity (out of $10)$ in the CRP group was $5.64 \pm 2.21$ and $5.38 \pm 2.35$ in the CWP group.

The relationship between sleep problems at 15 years of age and musculoskeletal pain at 17 years of age was examined using logistic regression (Tables 3 and 4). OR were calculated after adjusting for sex, ethnicity, socioeconomic status, depression at 15 years of age and current sleep problems at 17 years of age. Sleep disturbance (usually wakes more than two or three times) was associated with increased odds of both CRP (OR 1.81 [95\% CI 1.07 to 3.07]) and CWP (OR 2.13 [95\% CI 1.22 to 3.74]). Those who considered themselves to be 'poor sleepers' also had greater odds of developing CRP (OR 1.61 [95\% CI 1.01 to 2.58]) and CWP (OR 1.77 [95\% CI 1.07 to 2.91]). Those reporting big to very big difficulties with hypersomnolence were associated with CRP (OR 3.42 [95\% CI 1.62 to 7.22]) and CWP (OR 2.76 [95\% CI 1.05 to 7.25$]$ ). Finally, perceived quantity of sleep was only associated with CRP (OR 3.04 [95\% CI 1.18 to 7.79]).

Ordered logistic regression was used to assess the association between sleep and pain severity in those reporting CRP and CWP, in those with available data $(n=1147)$. Pain severity was ordered into the following categories: no pain to mild pain, moderate pain and severe pain. Problematic sleep was associated with greater pain severity in participants with both CRP ( $\mathrm{n}=115$; OR 2.78 [95\% CI 1.23 to 6.29]) and CWP ( $\mathrm{n}=100$; OR 2.46 [95\% CI 1.03 to 5.88]). The results suggest that subjective perceptions of being a 'poor sleeper' are associated with greater levels of musculoskeletal pain severity.

\section{DISCUSSION}

As hypothesized, our results are suggestive of an association between sleep problems during adolescence and musculoskeletal pain at a later time point. Poor subjective perceptions of sleep, states of hypersomnolence and higher degrees of disturbance were associated with the presence of CRP and CWP. Furthermore, for individuals experiencing musculoskeletal pain, participants describing themselves as poor sleepers at 15 years of age reported greater pain severity at 17 years of age.

Our results complement the previous literature showing an association between sleep problems and chronic musculoskeletal pain conditions. Studies of a Finnish cohort have found both hypersomnolence (40) and sleep disturbance to predict the development of musculoskeletal problems (2). A later study also found that both insufficient sleep quality and quantity were independent risk factors for the development of neck and lower back pain in females (21). Given this mounting evidence, it appears that poor sleep is indeed a potential risk factor for the development of musculoskeletal pain.

When one considers Lewin and Dahl's (41) proposed model of sleep problems and chronic pain in adolescence, it is possible to speculate on mechanisms whereby sleep problems can contribute to the development of musculoskeletal pain. Sleep disturbance can lay the foundations for a number of neurophysiological changes that can alter pain thresholds including increased sensitivity $(18,19)$. Not only does sleep influence brain maturation, but it also supports a number of biological and neurophysiological changes that occur during adolescence. Of particular importance are the effects that sleep disruption can have on the opioidergic system, immune and endocrinological processes. Dysfunctions in each of these systems have been linked to CWP (4245). While it is outside the scope of the present article to discuss these systems, it is possible to recognize how sleep problems may make adolescents neurophysiologically more vulnerable to the development of chronic illness, and in particular CRP and CWP.

Given that pain data were not available at 15 years of age, it is difficult to rule out the possibility that the adolescents had existing musculoskeletal difficulties. Nonetheless, the finding of greater pain severity in those with CRP and CWP who considered themselves poor sleepers was of particular interest. Previous studies have shown how negative perceptions of sleep (eg, ruminating over poor sleep quality) can influence pain severity in both adolescent and adult pain populations $(12,46)$. Such findings are relevant to the proposal that problematic sleep makes us more cognitively vulnerable to the detrimental psychological aspects of experiencing both acute and chronic pain (41). States of hypersomnolence can result from acute sleep loss, reducing both cognitive acuity and the drive to initiate behaviours or seek rewards. Emotional changes, such as low mood or frustration, are also observed in individuals who are sleep deprived (47). Such factors may reduce long-term pain-related rehabilitation goals.

Acute sleep loss can lead to attentional deficits such as impairments with sustained attention, vigilance and cognitive flexibility. In particular, individuals who are sleep deprived show a diminished capacity to exert control over their attentional focus (48). This means the ability to divert or reorientate attention away from sources of threat may be undermined and may indirectly contribute to increased pain severity. This, over time, may cause one to become hypervigilant to the threat of pain, meaning individuals will avoid particular activities that are perceived to cause pain. This can lead to a disabilityenhancing cycle, whereby those with sleep problems become more sedentary due to the increased threat of pain and reduced motivation which, therefore, reduces the likelihood of rehabilitation. Such factors may explain the association between early sleep problems and later comorbid musculoskeletal pain and sleep problems.

Although the complexity of the sleep-pain relationship in paediatric pain populations has been acknowledged $(41,49)$, we need to develop a better understanding of biopsychosocial factors related to sleep and pain. Studies objectively measuring the effects of sleep in adolescents have reported mixed findings (50-52). Further research using larger sample sizes and polysomographic measures are required to objectively test the findings from large epidemiological studies.

Although the present study has revealed some interesting associations, there are limitations to the interpretation of the results. First, because pain measures were not available at 15 years of age, it is difficult to rule out the possibility that the participants were already experiencing a pain-related illness. Second, both forms of musculoskeletal pain are likely to be associated with several comorbid developmental problems, and it may be impossible to separate them. The present study attempted to control for a number of these factors but early childhood influences could also have residual effects. Third, we must be cautious of overinterpreting the results, given that subjective self-report measures were used to ascertain information about the 
TABLE 3

Associations between different forms of sleep problems at 15 years of age and the development of chronic regional pain at 17 years of age

\begin{tabular}{|c|c|c|c|c|c|c|c|}
\hline \multirow[b]{2}{*}{ Types of sleep disturbance } & \multirow[b]{2}{*}{$\mathbf{n}$} & \multicolumn{2}{|c|}{ Unadjusted model } & \multicolumn{2}{|c|}{ Partially adjusted model ${ }^{\dagger}$} & \multicolumn{2}{|c|}{ Fully adjusted model ${ }^{\ddagger}$} \\
\hline & & OR & $\mathbf{P}$ & OR & $\mathbf{P}$ & OR & $\mathbf{P}$ \\
\hline \multicolumn{8}{|l|}{ Do you consider yourself a: } \\
\hline Good sleeper & 2114 & Reference & & Reference & & Reference & \\
\hline Poor sleeper & 379 & $1.84(1.18-2.85)$ & $<0.01^{* *}$ & $1.76(1.13-2.74)$ & $0.01^{*}$ & $1.61(1.01-2.58)$ & $0.04^{*}$ \\
\hline \multicolumn{8}{|l|}{ Usually wakes up: } \\
\hline Never & 1408 & Reference & & Reference & & Reference & \\
\hline Once & 759 & $1.45(0.95-2.21)$ & 0.08 & $1.36(0.89-2.08)$ & 0.16 & $1.31(0.84-2.05)$ & 0.23 \\
\hline $2-3$ times/>3 times & 326 & $2.07(1.25-3.41)$ & $<0.01^{\star *}$ & $1.85(1.20-3.07)$ & $0.02^{*}$ & $1.81(1.07-3.07)$ & $0.03^{*}$ \\
\hline \multicolumn{8}{|c|}{ Problems with hypersomnolence: } \\
\hline Never & 965 & Reference & & Reference & & Reference & \\
\hline A little & 1294 & $0.72(0.48-1.08)$ & 0.11 & $0.67(0.44-1.01)$ & 0.06 & $0.60(0.39-0.91)$ & $0.02^{*}$ \\
\hline More than a little & 174 & $0.90(0.42-1.94)$ & 0.79 & $0.83(0.38-1.78)$ & 0.63 & $0.67(0.30-1.53)$ & 0.34 \\
\hline Big/very big & 60 & $4.20(2.05-8.57)$ & $<0.001^{* *}$ & $3.79(1.84-7.80)$ & $<0.001^{* *}$ & $3.42(1.62-7.22)$ & $<0.001^{* *}$ \\
\hline \multicolumn{8}{|l|}{ Enough sleep: } \\
\hline Always & 269 & Reference & & Reference & & Reference & \\
\hline Usually & 1301 & $2.01(0.86-4.71)$ & 0.11 & $1.90(0.81-4.48)$ & 0.14 & $1.76(0.74-4.17)$ & 0.20 \\
\hline Sometimes & 648 & $2.13(0.88-5.17)$ & 0.10 & $1.94(0.79-4.75)$ & 0.15 & $1.81(0.74-4.47)$ & 0.20 \\
\hline Rarely/never & 275 & $4.00(1.60-9.98)$ & $<0.01^{* *}$ & $3.67(1.46-9.24)$ & $<0.01^{* *}$ & $3.04(1.18-7.79)$ & $0.02^{*}$ \\
\hline
\end{tabular}

${ }^{\dagger}$ Adjusted for sex, ethnicity and socioeconomic position, ${ }^{\ddagger}$ Additionally adjusted for depression (age 15$)$ and current sleep problems (age 17$) .{ }^{*} P<0.05 ;{ }^{* \star} P<0.01$; ${ }^{* * *} P<0.001$

TABLE 4

Associations between different forms of sleep problems at 15 years of age and the development of chronic widespread pain at 17 years of age

\begin{tabular}{|c|c|c|c|c|c|c|c|}
\hline \multirow[b]{2}{*}{ Types of sleep disturbance } & \multirow[b]{2}{*}{$\mathbf{n}$} & \multicolumn{2}{|l|}{ Unadjusted model } & \multicolumn{2}{|c|}{ Partially adjusted model ${ }^{\dagger}$} & \multicolumn{2}{|c|}{ Fully adjusted model ${ }^{\ddagger}$} \\
\hline & & OR & $\mathbf{P}$ & OR & $\mathbf{P}$ & OR & $\mathbf{P}$ \\
\hline \multicolumn{8}{|l|}{ Do you consider yourself a: } \\
\hline Good sleeper & 2114 & Reference & & Reference & & Reference & \\
\hline Poor sleeper & 379 & $1.89(1.19-3.02)$ & $<0.01^{* *}$ & $1.81(1.13-2.89)$ & $0.01^{*}$ & $1.77(1.07-2.91)$ & $0.03^{*}$ \\
\hline \multicolumn{8}{|l|}{ Usually wakes up: } \\
\hline Never & 1408 & Reference & & Reference & & Reference & \\
\hline Once & 759 & $1.71(1.09-2.69)$ & $0.02^{*}$ & $1.58(1.00-2.49)$ & 0.05 & $1.54(0.96-2.47)$ & 0.07 \\
\hline $2-3$ times $/>3$ times & 326 & $2.53(1.50-4.28)$ & $<0.001^{* \star *}$ & $2.23(1.31-3.80)$ & $<0.01^{* *}$ & $2.13(1.22-3.74)$ & $<0.01^{* *}$ \\
\hline \multicolumn{8}{|c|}{ Problems with hypersomnolence: } \\
\hline Never & 965 & Reference & & Reference & & Reference & \\
\hline A little & 1294 & $1.19(0.75-1.87)$ & 0.45 & $1.11(0.70-1.76)$ & 0.66 & $1.04(0.65-1.67)$ & 0.86 \\
\hline More than a little & 174 & $2.84(1.50-5.38)$ & $<0.001^{* * *}$ & $2.57(1.35-4.90)$ & $<0.01^{* *}$ & $2.32(1.18-4.54)$ & $0.01^{*}$ \\
\hline Big/very big & 60 & $3.35(1.34-8.37)$ & $0.01^{*}$ & $3.01(1.20-7.59)$ & $0.02^{*}$ & $2.76(1.05-7.25)$ & $0.04^{*}$ \\
\hline \multicolumn{8}{|l|}{ Enough sleep: } \\
\hline Always & 269 & Reference & & Reference & & Reference & \\
\hline Usually & 1301 & $0.73(0.38-1.41)$ & 0.35 & $0.66(0.34-1.34)$ & 0.22 & $0.63(0.32-1.23)$ & 0.18 \\
\hline Sometimes & 648 & $0.90(0.44-1.80)$ & 0.76 & $0.78(0.38-1.58)$ & 0.49 & $0.75(0.37-1.52)$ & 0.42 \\
\hline Rarely/never & 275 & $1.68(1.68-3.51)$ & 0.17 & $1.46(0.69-3.07)$ & 0.32 & $1.20(0.55-2.62)$ & 0.64 \\
\hline
\end{tabular}

${ }^{\dagger}$ Adjusted for sex, ethnicity and socioeconomic position; ${ }^{\ddagger}$ Additionally adjusted for depression (15 years of age) and current sleep problems (17 years of age). ${ }^{*} P<0.05 ;{ }^{* *} P<0.01 ;{ }^{* *} P<0.001$

adolescents' sleep patterns. In particular, care must be taken when interpreting the subjective perception of sleep given how they were assessed; for example, the metric assessing 'sleep disturbance' does not provide us with a quantitative index of sleep disturbance. Furthermore, different measures were used to assess sleep at the two time points; however, both provided suitable indexes of problematic sleep. Objective, longitudinal and translational studies are needed to elucidate the influence of adolescent sleep patterns on brain development, physiological processes and the development of musculoskeletal pain. Despite these limitations, the factors that may be contributing to sleep problems at 15 years of age may play a part in the presence of musculoskeletal pain at 17 years of age.

The low prevalence of both CWP and CRP in our sample must be acknowledged. Given that previous studies have revealed a wide range in the prevalence estimates (4\% to $40 \%$ ) of musculoskeletal pain in adolescence, this may speak to the different measures and scales used to assess musculoskeletal pain. For example, Auvinen et al (21) reported high prevalence estimates of musculoskeletal pain ( $42 \%$ to $52 \%$ ) based on a dichotomous response to a single item measure. The criterion used for CWP in the present study is consistent with the diagnostic criteria for fibromyalgia. Whereas tenderness on clinical examination (not recorded in present study) is usually included, this has recently been dropped in the revised American College of Rheumatology criteria (53). Our findings could, therefore, have important implications for adolescents with juvenile fibromyalgia. However, both longitudinal and objective measures are required to better establish the role of sleep in such pain populations. Adolescents already face abrupt variations in their sleep pattern because sleep-wake 
schedules rapidly change across weekdays and weekends. It is especially important to catch sleep problems early in adolescence because sleep disruption is reported to become worse as the teenager moves into young adulthood (7). Modern societies also pose a significant risk factor for prolonged sleep disturbance. For example, increased societal pressures may result in various anxieties, which can impact both sleep onset and continuity. The increased availability of pharmacological stimulants such as caffeine may also mean adolescents get less sleep. Similarly, availability of electronic stimulation, such as television and the Internet (particularly on smartphones), in the bedroom is becoming more commonplace, meaning there is a trend for adolescents to delay sleep, but still wake up for school. Over the decade, sleep restriction or disturbance is only likely to become more prevalent and, unfortunately, problematic.

Our results would suggest that the treatment of sleep problems in adolescents is of clinical relevance. Problematic sleep is associated with both impaired physiological and psychological well-being (54), the consequences of which could be detrimental to an adolescent's emotional, social and educational development. Such maladaptive development could subsequently make adolescents more vulnerable to chronic illness as they progress into adulthood $(55,56)$. Dealing with the psychological aspects of problematic sleep may also be beneficial for adolescents with musculoskeletal problems. For example, cognitive behavioural therapy with a focus on sleep was found to be effective in alleviating pain symptoms and improving quality of life in adolescents with musculoskeletal pain conditions (57).

\section{REFERENCES}

1. Singh GK, Kenney MK. Rising prevalence and neighborhood, social, and behavioral determinants of sleep problems in US children and adolescents, 2003-2012. Sleep Disord 2013;2013:394320.

2. El-Metwally A, Salminen JJ, Auvinen A, Kautiainen H, Mikkelsson M. Prognosis of non-specific musculoskeletal pain in preadolescents: A prospective 4-year follow-up study till adolescence. Pain 2004;110:550-9.

3. Auvinen JP, Tammelin TH, Taimela SP, et al. Is insufficient quantity and quality of sleep a risk factor for neck, shoulder and low back pain? A longitudinal study among adolescents. Eur Spine J 2010;19:641-9.

4. Meltzer LJ, Logan DE, Mindell JA. Sleep patterns in female adolescents with chronic musculoskeletal pain. Behav Sleep Med 2005;3:193-208.

5. Millman RP. Excessive sleepiness in adolescents and young adults: Causes, consequences, and treatment strategies.

Pediatrics 2005;115:1774-86.

6. Hysing M, Pallesen S, Stormark KM, Lundervold AJ, Sivertsen B. Sleep patterns and insomnia among adolescents: A population-based study. J Sleep Res 2013;22:549-56.

7. Ohayon MM, Roberts RE, Zulley J, Smirne S, Priest RG. Prevalence and patterns of problematic sleep among older adolescents. J Am Acad Child Adolesc Psychiatry 2000;39:1549-56.

8. Roberts R, Roberts C, Chen I. Functioning of adolescents with symptoms of disturbed sleep. J Youth Adolescence 2001;30:1-18.

9. National Sleep Foundation. Adolescent sleep needs and patterns. 2000. <www.sleepfoundation.org> (Accessed August 28, 2013).

10. Pieh C, Popp R, Geisler P, Hajak G. [Sleep and pain: A bi-directional relation?]. Psychiatr Prax 2011;38:166-70.

11. Smith MT Haythornthwaite JA. How do sleep disturbance and chronic pain inter-relate? Insights from the longitudinal and cognitive-behavioral clinical trials literature. Sleep Med Rev 2004;8:119-32.

12. Smith MT, Perlis ML, Smith MS, Giles DE, Carmody TP. Sleep quality and presleep arousal in chronic pain. J Behav Med 2000;23:1-13.

13. Affleck G, Urrows S, Tennen H, Higgins P, Abeles M. Sequential daily relations of sleep, pain intensity, and attention to pain among women with fibromyalgia. Pain 1996;68:363-8.

14. Gupta A, Silman AJ, Ray D. The role of psychosocial factors in predicting the onset of chronic widespread pain: Results from a prospective population-based study. Rheumatology 2007;46:666-71.

15. Davies KA, Macfarlane GJ, Nicholl BI, et al. Restorative sleep predicts the resolution of chronic widespread pain: Results from the EPIFUND study. Rheumatology 2008;47:1809-13.
Both sleep problems and, importantly, musculoskeletal pain conditions can cause a deviation in an adolescent's normal developmental trajectory. The present study complements previous research in suggesting that sleep is a modifiable risk factor for musculoskeletal pain. Given the risks associated with sleep problems, sleep should be considered as a potential therapeutic target in both the prevention and management of certain illnesses and, in particular, musculoskeletal conditions.

ACKNOWLEDGEMENTS: The authors are extremely grateful to all the families who participated in this study, the midwives for their help in recruiting them, and the entire ALSPAC team, which includes interviewers, computer and laboratory technicians, clerical workers, research scientists, volunteers, managers, receptionists and nurses. The UK Medical Research Council, the Wellcome Trust (Grant ref: 092731) and the University of Bristol provide core support for ALSPAC. This publication is the work of the authors and Lee Harrison will serve as guarantor for the contents of this article. MRM is a member of the United Kingdom Centre for Tobacco and Alcohol Studies, a UKCRC Public Health Research: Centre of Excellence. Funding from British Heart Foundation, Cancer Research UK, Economic and Social Research Council, Medical Research Council, and the National Institute for Health Research, under the auspices of the UK Clinical Research Collaboration, is gratefully acknowledged.

DISCLOSURES: The authors have no relevant conflicts of interest to declare.

16. King S, Chambers CT, Huguet A, et al. The epidemiology of chronic pain in children and adolescents revisited: A systematic review. Pain 2011;152:2729-38.

17. Knook LM, Konijnenberg AY, van der Hoeven J, et al. Psychiatric disorders in children and adolescents presenting with unexplained chronic pain: What is the prevalence and clinical relevancy? Eur Child Adolesc Psychiatry 2011;20:39-48

18. Kundermann B, Krieg JC, Schreiber W, Lautenbacher S. The effect of sleep deprivation on pain. Pain Res Manag 2004;9:25-32.

19. Onen SH, Alloui A, Gross A, Eschallier A, Dubray C. The effects of total sleep deprivation, selective sleep interruption and sleep recovery on pain tolerance thresholds in healthy subjects. J Sleep Res 2001;10:35-42.

20. Paananen MV, Auvinen JP, Taimela SP, et al. Psychosocial, mechanical, and metabolic factors in adolescents' musculoskeletal pain in multiple locations: A cross-sectional study. Eur J Pain 2010;14:395-401.

21. Auvinen JP, Tammelin TH, Taimela SP, et al. Is insufficient quantity and quality of sleep a risk factor for neck, shoulder and low back pain? A longitudinal study among adolescents. Eur Spine J 2010;19:641-9.

22. Smith MT, Klick B, Kozachik S, et al. Sleep onset insomnia symptoms during hospitalization for major burn injury predict chronic pain. Pain 2008;138:497-506.

23. Mork PJ, Nilsen TI. Sleep problems and risk of fibromyalgia: Longitudinal data on an adult female population in Norway. Arthritis Rheum 2012;64:281-4.

24. Boyd A, Golding J, Macleod J, et al. Cohort profile: The 'Children of the 90s' - the index offspring of the Avon Longitudinal Study of Parents and Children. Int J Epidemiol 2012;42:111-27.

25. Mallen CD, Peat G, Thomas E, Croft PR. Is chronic musculoskeletal pain in adulthood related to factors at birth? A population-based case-control study of young adults. Eur J Epidemiol 2006;21:237-43.

26. Parsons S, Carnes D, Pincus T, et al. Measuring troublesomeness of chronic pain by location. BMC Musculoskelet Disord 2006;7:34.

27. Von Korff M, Ormel J, Keefe FJ, Dworkin SF. Grading the severity of chronic pain. Pain 1992;50:133-49.

28. Deere KC, Clinch J, Holliday K, et al. Obesity is a risk factor for musculoskeletal pain in adolescents: Findings from a populationbased cohort. Pain 2012;153:1932-8.

29. Wolfe F, Smythe HA, Yunus MB, et al. The American College of Rheumatology 1990 Criteria for the Classification of Fibromyalgia. Arthritis Rheum 1990;33:160-72.

30. Lewis G, Pelosi AJ, Araya R, Dunn G. Measuring psychiatric disorder in the community: A standardized assessment for use by lay interviewers. Psychol Med 1992;22:465-86. 
31. Patto GC, Coffey C, Posterino M, Carlin JB, Wolfe R, Bowes G. A computerised screening instrument for adolescent depression: Population-based validation and application to a two-phase casecontrol study. Soc Psychiatry Psychiatr Epidemiol 1999;34:166-72.

32. Bell T, Watson M, Sharp D, Lyons I, Lewis G. Factors associated with being a false positive on the General Health Questionnaire. Soc Psychiatry Psychiatr Epidemiol 2005;40:402-7.

33. Brugha TS, Meltzer H, Jenkins R, Bebbington PE, Taub NA. Comparison of the CIS-R and CIDI lay diagnostic interviews for anxiety and depressive disorders. Psychol Med 2005;35:1089-91.

34. Brugha TS, Morgan Z, Bebbington P, et al. Social support networks and type of neurotic symptom among adults in British households. Psychol Med 2003;33:307-18.

35. Stanford EA, Chambers CT, Biesanz JC, Chen E. The frequency, trajectories and predictors of adolescent recurrent pain: A population-based approach. Pain 2008;138:11-21.

36. Mustard CA, Kalcevich C, Frank JW, Boyle M. Childhood and early adult predictors of risk of incident back pain: Ontario Child Health Study 2001 follow-up. Am J Epidemiol 2005;162:779-86.

37. Moore M, Kirchner HL, Drotar D, Johnson N, Rosen C, Redline S. Correlates of adolescent sleep time and variability in sleep time: The role of individual and health related characteristics. Sleep Med 2011;12:239-45.

38. Goodman R, Ford T, Richards H, Gatward R, Meltzer H. The Development and Well-Being Assessment: Description and initial validation of an integrated assessment of child and adolescent psychopathology. J Child Psychology Psychiatry 2000;41:645-55.

39. ALSPAC Data Dictionary. < www.bris.ac.uk/alspac/researchers/dataaccess/data-dictionary/> (Accessed March 2014).

40. Mikkelsson M, Sourander A, Piha J, Salminen JJ. Psychiatric symptoms in preadolescents with musculoskeletal pain and fibromyalgia. Pediatrics 1997;100:220-7.

41. Lewin DS, Dahl RE. Importance of sleep in the management of pediatric pain. J Dev Behav Pediatr 1999;20:244-52.

42. Heffner KL, France CR, Trost Z, Ng HM, Pigeon WR. Chronic low back pain, sleep disturbance, and interleukin-6. Clin J Pain 2011;27:35-41.

43. Marchand F, Perretti M, McMahon SB. Role of the immune system in chronic pain. Nat Rev Neurosci 2005;6:521-32.

44. Vgontzas AN, Chrousos GP. Sleep, the hypothalamic-pituitary-adrenal axis, and cytokines: Multiple interactions and disturbances in sleep disorders. Endocrinol Metabolism Clin North Am 2002;31:15-36.

45. McBeth J, Silman AJ, Gupta A. Moderation of psychosocial risk factors through dysfunction of the hypothalamic-pituitary-adrenal stress axis in the onset of chronic widespread musculoskeletal pain: Findings of a population-based prospective cohort study. Arthritis Rheum 2007;56:360-71.

46. Siu YF, Chan S, Wong KM, Wong WS. The comorbidity of chronic pain and sleep disturbances in a community adolescent sample: Prevalence and association with sociodemographic and psychosocial factors. Pain Med 2012;13:1292-303.

47. Palermo TM, Kiska R. Subjective sleep disturbances in adolescents with chronic pain: Relationship to daily functioning and quality of life. J Pain 2005;6:201-7.

48. Lewin DS, Rosen RC, England SJ, Dahl RE. Preliminary evidence of behavioral and cognitive sequelae of obstructive sleep apnea in children. Sleep Med 2002;3:5-13.

49. Valrie CR, Bromberg MH, Palermo T, Schanberg LE. A systematic review of sleep in pediatric pain populations. J Dev Behav Pediatr 2013;34:120-8.

50. Lewandowski AS, Palermo TM, De la Motte S, Fu R. Temporal daily associations between pain and sleep in adolescents with chronic pain versus healthy adolescents. Pain 2010;151:220-5.

51. Haim A, Pillar G, Pecht A. Sleep patterns in children and adolescents with functional recurrent abdominal pain: Objective versus subjective assessment. Acta Paediatr 2004;93:677-80.

52. Palermo TM, Objective and subjective assessment of sleep in adolescents with chronic pain compared to healthy adolescents. Clin J Pain 2007;23:812-20.

53. Wolfe F, Clauw DJ, Fitzcharles MA, et al. The American College of Rheumatology preliminary diagnostic criteria for fibromyalgia and measurement of symptom severity. Arthritis Care Res (Hoboken) 2010;62:600-10.

54. Kyle SD, Morgan K, Espie CA. Insomnia and health-related quality of life. Sleep Med Rev 2010;14:69-82.

55. Kashikar-Zuck S, Goldschneider KR, Powers SW, Vaught MH, Hershey AD. Depression and functional disability in chronic pediatric pain. Clin J Pain 2001;17:341-9.

56. Fombonne E, Wostear G, Cooper V, Harrington R, Rutter M. The Maudsley long-term follow-up of child and adolescent depression. 2. Suicidality, criminality and social dysfunction in adulthood. Br J Psychiatry 2001;179:218-23.

57. Degotardi PJ, Klass ES, Rosenberg BS, Fox DG, Gallelli KA, Gottlieb BS. Development and evaluation of a cognitive-behavioral intervention for juvenile fibromyalgia. J Pediatr Psychol 2006;31:714-23. 


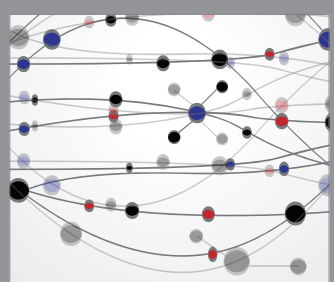

The Scientific World Journal
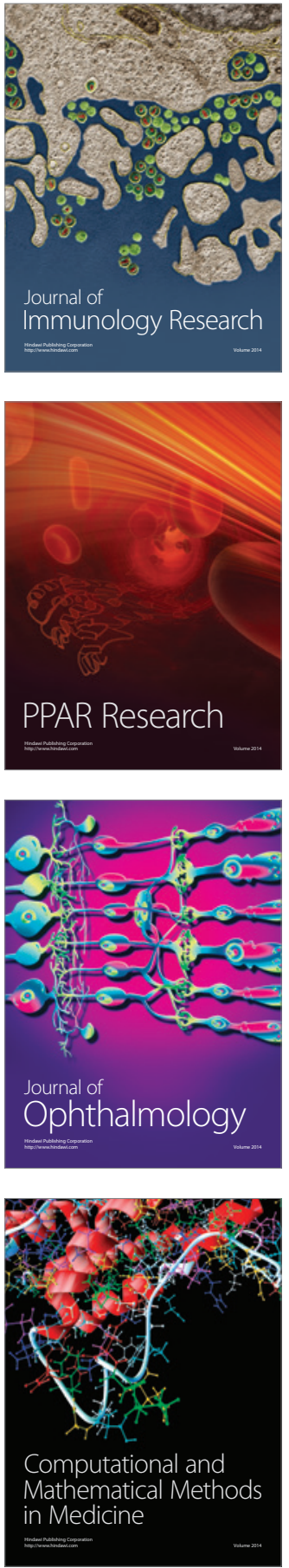

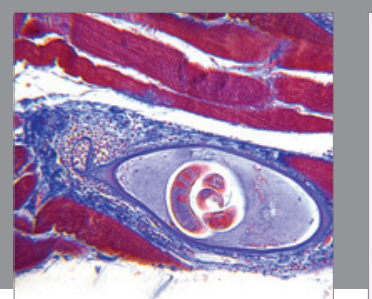

Gastroenterology Research and Practice

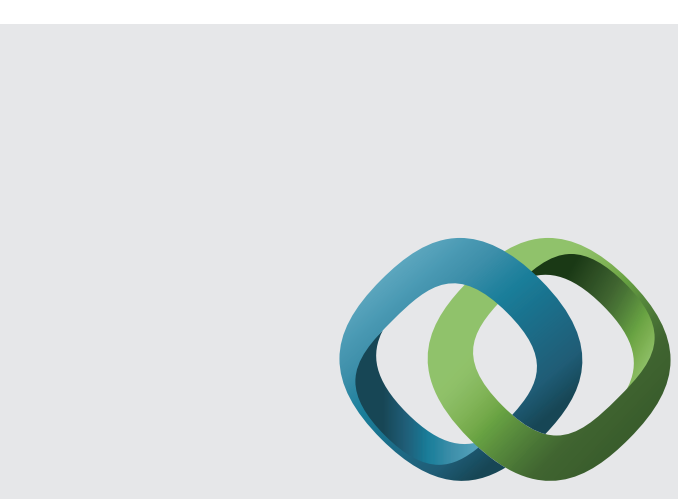

\section{Hindawi}

Submit your manuscripts at

http://www.hindawi.com
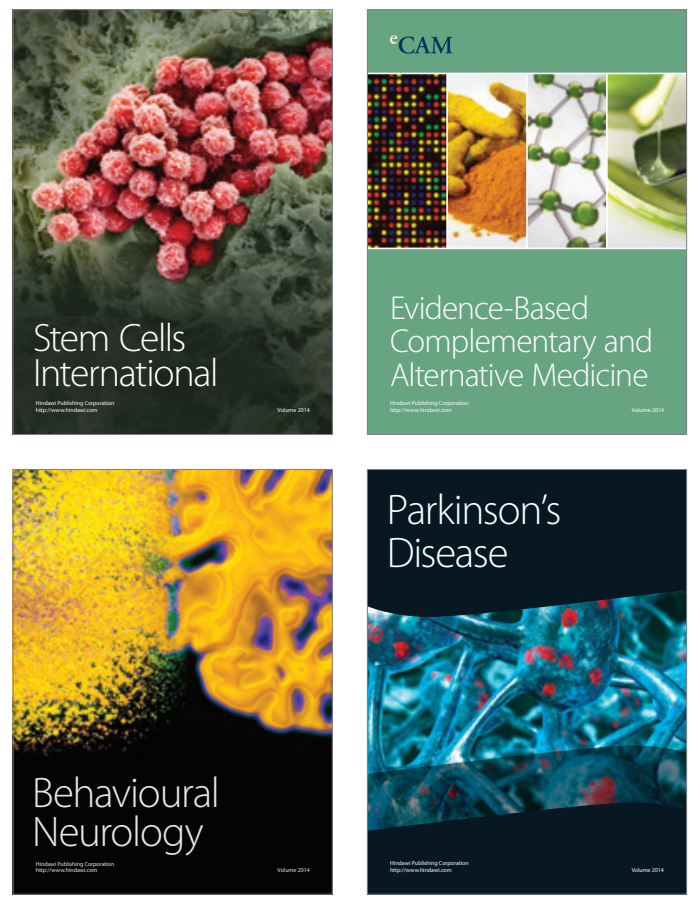
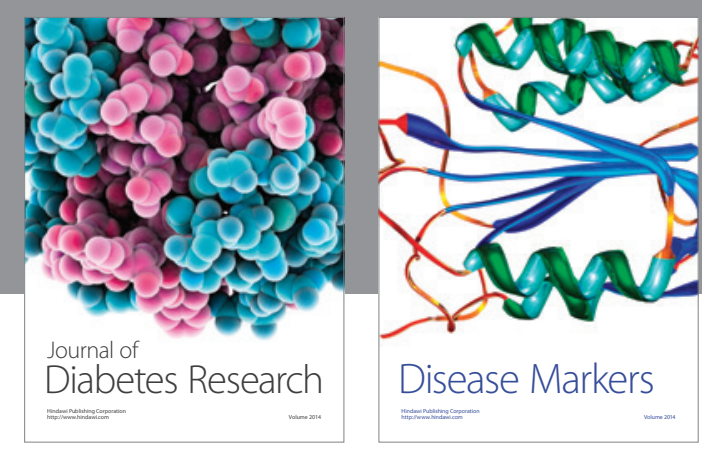

Disease Markers
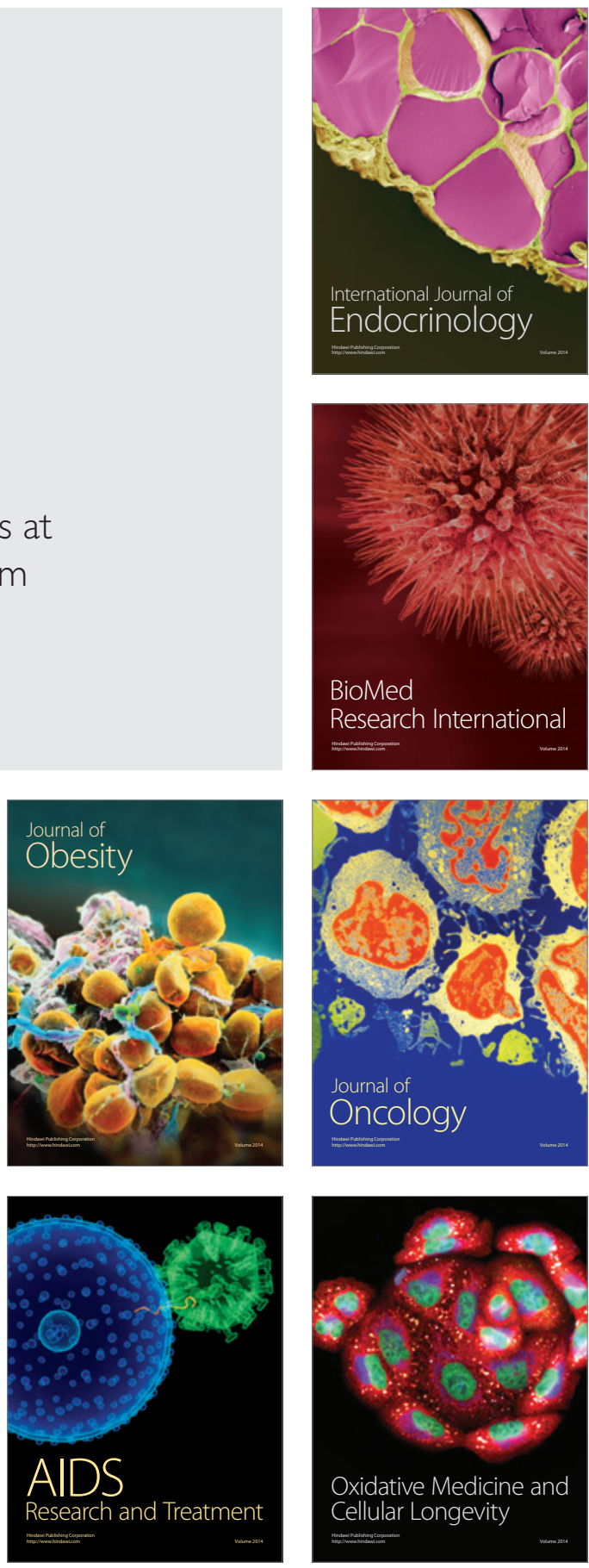